\title{
O ENSINO MÉDIO MINISTRADO NO CENTRO EDUCACIONAL PATATIVA DO ASSARÉ
}

\author{
L. M. F. FIALHO \\ Universidade Federal do Ceará \\ E-mail: lia_fialho@yahoo.com.br
}

Artigo submetido em março/2012 e aceito em maio/2012

\section{RESUMO}

O Centro Educacional Patativa do Assaré (CEPA) é uma unidade de "ressocialização" para jovens de dezessete anos em conflito com a lei do sexo masculino que cumprem medida socioeducativa de internação, na cidade de Fortaleza, Ceará. Foi adotada a abordagem qualitativa (MINAYO, 2003) para realizar um estudo de caso referente à educação escolar ministrada no CEPA, com entrevistas e diário de campo como procedimentos metodológicos. Através da observação foi possível averiguar que a instituição possui cinco salas de aula adequadas, mas os alunos só desfrutam de duas horas diárias de aula. $\mathrm{O}$ ensino médio é ministrado através do
Ensino de Jovens e Adultos (EJA), independente da distorção entre série e idade, respeitando um sistema interno de rodízio. A análise das entrevistas, com os sete participantes, possibilitou constatar que: a frequência às salas de aula configura a atividade mais desejada pelos jovens; a educação escolar é suspensa sempre que eles são punidos por comportamento disciplinar indesejado; o tempo de aula é insuficiente; e a educação não contempla sua finalidade legal de desenvolver o educando para o exercício da cidadania e para a progressão em estudos posteriores.

\section{GIVEN IN SECONDARY EDUCATION CENTER EDUCATIONAL PATATIVA DO ASSARÉ}

\section{ABSTRACT}

The Educational Center Patativa do Assaré (CEPA) is a unit of "rehabilitation" for seventeen-yearold male juveniles in conflict with the law who pay social educative measure of detention, in Fortaleza, Ceará. We adopted a qualitative approach (MINAYO, 2003) to conduct a case study related to school education taught in the CEPA, with interviews and field journal as instruments. Through observation it was possible to as certain that the institution has five appropriate classrooms, but students only enjoy daily two hours of class. The school is administered through the Education for Youths and Adults (EJA), regardless of the distortion between grade and age, respecting a system of internal rotation. The analysis of interviews with seven participants, allowed establishing that: the frequency to the classroom configures the most desired activity by young people; school education is suspended when they are punished for disciplinary unwanted behavior; the classroom time is insufficient; and education does not address their statutory purpose of developing the student for citizenship and progression in further studies.

KEY-WORDS: petroleum, environmental risks, drilling rig, the risk maps. 


\section{O ENSINO MÉDIO MINISTRADO NO CENTRO EDUCACIONAL PATATIVA DO ASSARÉ}

\section{INTRODUÇÃO}

O aumento da infração envolvendo jovens com idades inferiores a dezoito anos; a aparente precariedade dos recursos financeiros e de pessoal qualificado para efetivar políticas centradas em reverter a situação de violência juvenil; a superlotação de instituições destinadas ao atendimento do público jovem em conflito com a lei; as altas taxas de reincidência infracional; o questionável caráter ressocializador dos centros de atendimento aos jovens internos, dentre outras nuances que perpassam a problemática da violência juvenil, põem em cheque a funcionalidade do sistema socioeducativo que atende esse público. E em contrapartida ao fundamento ressocializador, humanitário e educativo, os atuais debates sobre o Estatuto da Criança e do Adolescente (ECA) discutem projetos de redução da maioridade penal e recrudecimento das ações aplicadas aos menores. Essa possibilidade, fundamentada no discurso de que a ressocialização não está funcionando e de que a violência envolvendo jovem cresce largamente, permite averiguar a existência de lacunas no trato com a educação e assistência da juventude em conflito com a lei. Logo, julga-se relevante a realização de estudos acerca da violência na juventude, consistindo esta em um problema social que aflige a população brasileira de maneira geral (PRIULI, MORAES, 2007; OLIVEIRA, ASSIS, 1999; EDUARDO, EGRY, 2010; BRANCO, WAGNER, 2009).

$\mathrm{Na}$ condição de pedagoga, aflita e comprometida com a educação de crianças e adolescentes em instituições socioeducativas e incomodada com a maneira como o Estado vem tratando a problemática do jovem em conflito com a lei, a pesquisadora justifica a relevância do presente estudo em virtude da necessidade de conhecer a educação ministrada nos centros de internação sob a ótica dos jovens usuários desse serviço para compreender as razões pelas quais se questiona a eficácia da ressocialização. Permitindo que aqueles, que se configuram o foco do processo socioeducativo, possam opinar sobre as ações de educação direcionadas a eles.

Muitas perguntas pertinentes devem ser elaboradas e analisadas acerca dessa temática, mas uma pode ser considerada a problemática chave do presente estudo: como os jovens em conflito com a lei, internados em instituição socioeducativa, concebem a experiência educativa vivenciada por intermédio da escolarização? Desse modo, o escopo do estudo é compreender, sob a ótica do interno, a escolarização dos jovens em conflito com a lei do Centro Educacional Patativa do Assaré - CEPA. Para tanto, realiza-se uma pesquisa de abordagem qualitativa que utiliza o caminho metodológico da história oral temática colhida por intermédio de entrevista semiestruturada.

\section{AS MEDIDAS SOCIOEDUCATIVAS}

Quando acusado de praticar um ato infracional, pego em flagrante, o adolescente é encaminhado à delegacia da infância e juventude mais próxima do local da ocorrência. Depois de registrada a infração, o juiz da vara responsável aplica uma das determinações legais, intituladas de medidas socioeducativas.

A medida socioeducativa é uma determinação legal imposta pelo juiz da infância e da juventude ao adolescente que comprovadamente comete um ato infracional, visando a 
ressocializá-lo por sua conduta antissocial. Deve possuir dimensão punitiva e educativa ao mesmo tempo, visando prioritariamente ao caráter educativo em detrimento do sancionatório. Tais medidas devem ser determinadas levando em consideração a gravidade da infração cometida, as circunstâncias em que esta fora praticada e a capacidade do adolescente de cumprir aquelas, priorizando medidas em que o jovem permaneça no convívio familiar e social no qual está inserido.

Há seis medidas socioeducativas que a autoridade judiciária pode aplicar ao adolescente, autor do ato infracional: 1) Advertência, que se aplica ao adolescente infrator primário que comete um ato infracional de pouca gravidade; 2) Obrigação de reparar o dano, que consiste em restituição, ressarcimento ou compensação do dano ou do prejuízo causado à vítima; 3) Prestação de serviço à comunidade, que se trata da realização de tarefas gratuitas de interesse social, por período inferior a seis meses, em entidades assistenciais; 4) Liberdade assistida, que se destina aos jovens que aparentemente são passíveis de recuperação em meio livre e que estão se iniciando no processo infracional; 5) Inserção em regime de semiliberdade, que se aplica como tratamento tutelar designado desde o início, ou como progressão de medida da internação à liberdade, sendo esta última mais frequente; e 6) Internação em estabelecimento educacional, que consiste na privação de liberdade e no controle de ir e vir do adolescente, vinculando-o a um estabelecimento especializado, próprio para essa finalidade, e exclusivo para adolescentes, observando os critérios de idade, compleição física e gravidade da infração.

Configura-se necessário conhecer todas as medidas socioeducativas com suas características, bem como perceber as situações em que elas se aplicam, para facilitar a compreensão do atual sistema socioeducativo. Todavia, como o estudo define seu foco na análise da escolarização em uma instituição de internação, a pesquisa deter-se-á a discutir a última medida supracitada mais detalhadamente.

Dentre as medidas socioeducativas previamente explicitadas, as quatro primeiras são cumpridas em meio aberto e as duas últimas são restritivas de liberdade. Entretanto a única que priva realmente a liberdade do infrator, alterando totalmente sua rotina de vida e impondo-lhe vigília assídua e constante, é a de Internação. Assim esta medida merece atenção especial na sua execução e exige inúmeros cuidados particulares para que seja garantida a "humanização da punição", como determina a lei.

A internação, apesar de imposta para cumprimento em período pré-estabelecido de seis a três anos, não comporta prazo determinado, pois sua manutenção deve ser reavaliada, mediante decisão fundamentada, no máximo a cada seis meses. Depois de atingido o limite máximo de tempo - três anos -, o adolescente deverá ser liberado da internação e colocado em regime de semiliberdade ou de liberdade assistida.

Como a internação constitui medida privativa da liberdade é "sujeita aos princípios de brevidade, excepcionalidade e respeito à condição peculiar de pessoa em desenvolvimento" (art.121). Ou seja, caracteriza-se: por ser imposta em casos extremos; pelo menor período de tempo possível; e possibilitar a ressocialização, fundamentada no argumento de que o adolescente ainda está em processo maturador e pode modificar sua conduta a ponto de não reincidir em atitudes antissociais.

A medida de internação, por ser a mais severa, costuma ser aplicada depois de constatada reincidência infracional ou em casos extremos de primeira infração, quando há extrema 
gravidade no delito e flagrante. No entanto, os primeiros passos do trâmite legal, geralmente, são semelhantes aos aplicados para qualquer outra infração.

De acordo com o ECA, art. 106, "nenhum adolescente será privado de sua liberdade senão em flagrante de ato infracional ou por ordem escrita e fundamentada da autoridade judiciária competente", bem como ocorre com qualquer cidadão em tal circunstâncias.

\section{O CENTRO EDUCACIONAL PATATIVA DO ASSARÉ - CEPA}

A inauguração do CEPA data de 02 de abril de 2002. Nesse período, o secretário de trabalho e ação social era Edilson Azim Sarriune que pleiteou - articulando-se com outros setores da sociedade - junto ao governador do estado do Ceará, excelentíssimo senhor Tasso Ribeiro Jereissati, a construção de novas instituições para atender os menores infratores, já que as existentes não suportavam a demanda, permanecendo superlotadas e sem condições estruturais de assegurar humanização e qualidade de atendimento. Com financiamento do Banco Interamericano de Desenvolvimento (BID), a obra foi concluída com sucesso, em prazo maior que o esperado, para atender sessenta adolescentes em regime de internação provisória.

O CEPA possui uma estrutura física muito semelhante àquela definida pela Lei $n^{\circ} 8.666 / 93$, que regulamenta os projetos arquitetônicos para construção, ou reforma, de unidades de sócioatendimento especificados em documento federal, intitulado Sistema Nacional de Atendimento Socioeducativo (Sinase). Entretanto, configura-se necessário esclarecer que o atendimento pelo corpo técnico e a própria estrutura física se mostram insuficientes no cumprimento das determinações legais, por conta da superlotação. Afinal, uma estrutura projetada para 60 internos que funciona com média anual superior ao triplo dessa quantidade fica impossibilitada de trabalhar dentro da legalidade.

A área interna do CEPA pode ser subdividida em duas partes: a área administrativa, referente aos espaços utilizados pelo corpo técnico; e a área coletiva, onde os internos circulam diariamente.

A área administrativa possui diversas salas: da recepção, do monitoramento, da copa, das reuniões, da secretaria, da administração, da pedagogia, do serviço social, da psicologia, da enfermaria, da cozinha e do setor jurídico. É oportuno salientar que todas as salas do corpo técnico possuem uma boa estrutura, com espaço suficiente para o desenvolvimento do trabalho, climatização, iluminação, armários e computadores em funcionamento satisfatórios. Esses ambientes profissionais recebem os adolescentes individualmente para entrevista, avaliação e acompanhamento, bem como os respectivos responsáveis legais, quando se faz necessário. Em nenhum momento, houve relato negativo dos funcionários quanto ao espaço físico do ambiente de trabalho.

A área coletiva possui ambientes variados: seis blocos com cinco dormitórios, um bloco denominado de tranca, cinco salas de aula, cinco salas de oficinas, uma sala de material esportivo e recreativo, a lavanderia, o auditório, o campo de futebol, a quadra coberta, o pátio, a sala de visitas, o refeitório e o espaço ecumênico.

Observa-se que o espaço físico da instituição, como um todo, é muito bom. O grande problema é a superlotação, que impossibilita o trato para com os internos dentro dos padrões da legalidade, pois fisicamente é possível acomodar, com o mínimo de salubridade e conforto os 60 jovens como previa o projeto desenvolvido. O problema consiste em alojar cerca de 200 meninos 
em espaço projetado para 60. A superlotação na instituição faz com que um dormitório, planejado para dois, seja ocupado por no mínimo três e no máximo nove pessoas, tornando o ambiente extremamente apertado, desconfortável e desumano.

Segundo a Lei Federal 8.069/1990 (ECA), os jovens privados de liberdade possuem o direito dehabitar alojamento em condições adequadasde higiene e salubridade, entretanto, principalmente nas celas, a lotação ocasiona o descumprimento forçado da lei.

\section{TRAJETÓRIA DA PESQUISA}

Participaram da pesquisa sete jovens internados no CEPA, enquanto cumpriam medida socioeducativa de privação de liberdade, que concordarem em colaborar com estudo mediante garantia de sigilo de identidade. A escolha dos jovens foi aleatória, entretanto se assegurou a representação de todos os blocos da unidade.

O estudo utiliza o caminho metodológico da historia oral temática. Esse percurso metodológico foi escolhido pela necessidade e possibilidade de ouvir os sujeitos envolvidos no processo de "ressocialização", captar suas experiências e perceber as nuances pertinentes à educação escolar. Afinal, a história oral representa uma abordagem pouco convencional de pesquisa, mas propicia um olhar mais criterioso e fidedigno sobre a temática. Acerca da historia oral, Mesquita e Fonseca afirmam que:

[...] como metodologia e técnica de investigação, propicia a narração, pois o ato de rememorar promove o encontro entre os sujeitos para compartilhar experiências, registrá-las e divulgá-las sob a forma oral e escrita. A recuperação da narração suscita e (re)constrói memórias que estimulam análises e discussões sobre situações individuais e coletivas, compreendidas a partir do contexto social, pois o que nós pensamos, vivemos e sentimos, está intimamente ligado ao(s) outro(s) (2006, p.334).

Ouvir a história de vida dos envolvidos no processo de ressocialização, apesar de exigir uma dedicação maior do pesquisador e dos sujeitos investigados, permite a troca de experiências e a narração, o que possibilita o registro e a divulgação de um novo olhar acerca das vivências pessoais e coletivas. Configura-se oportuno, pois, fazer vir à tona o que ainda não havia sido registrado ou o que foi, muitas vezes, expurgado dos depósitos de memória. Ora, ao longo da história da humanidade, que se caracterizou por muitas vezes só ressaltar os fatos na perspectiva do poder, elegendo "heróis" e seus feitos, a voz da grande massa social permanece esquecida e inoperante. Le Goff destaca: "Cabe, com efeito, aos profissionais científicos da memória, antropólogos, historiadores, jornalistas, sociólogos, fazer a luta pela democratização da memória social..." (2003, p.471). Com efeito, a história oral possibilitou a aquisição do discurso do ator, que foi gravado digitalmente e transcrito respeitando suas palavras, registrando, na medida do possível, emoções, silêncios, e demais observações pertinentes. A proposta foi debruçar-se na realização de uma transcrição a mais precisa possível, concordando com Vidigal quando relata que:

A oralidade 'cativada' no registro áudio só se transforma numa fonte acessível quando é 'reconvertida' em documento escrito. E a transcrição suscita inúmeros problemas, inúmeras perdas, pois é sempre uma tradução para outro suporte, quase para outro idioma (1996, p. 73). 
Necessita-se elucidar que, mesmo compreendendo que a história oral não se caracteriza por ser um retrato fiel de fatos ocorridos, certamente evidencia interpretações muito pessoais construídas ao longo da trajetória de vida de cada um sob circunstâncias particulares. Afinal, os acontecimentos são contados através dos filtros culturais que a própria sociedade constrói, mas é por intermédio deles que se pode realizar uma reflexão mais rica acerca dos imbricamentos pertinentes à escolarização do jovem em conflito com a lei.

A pesquisa em educação requer uma busca criteriosa de evidências para que o pesquisador não caia nas armadilhas do uso quase que exclusivo das fontes oficiais, e apenas as reproduza. Logo, essa investigação se preocupa em ir além das pesquisas bibliográficas e da análise histórico-documental, no intuito de evocar memórias, colher relatos, que possam analiticamente descrever os conflitos e as contradições oriundos da vivência de uma escolarização em regime de ressocialização em unidade de privação de liberdade.

Interessa esclarecer que os funcionários da instituição que atendem os jovens também participaram da pesquisa, mas de maneira secundária: fornecendo material solicitado, esclarecendo dúvidas sobre o serviço de apoio oferecido, ou prestando outras informações pertinentes ao trabalho da pesquisadora. Ratifica-se ainda que este estudo se configura parte constituinte de uma pesquisa maior em andamento que objetiva compreender o significado da internação na história de vida do jovem em conflito com a lei.

\section{A EDUCAÇÃO ESCOLAR NO CEPA: RESULTADOS E DISCUSSÃO}

De acordo com o Sinase, os centros que atendem jovens em conflito com a lei em regime de internação deveriam possuir escola formal interna com secretária, coordenação e direção escolar, salas de aulas, projeto pedagógico, professores capacitados e materiais didáticos adequados às necessidades dos alunos. Entretanto, o CEPA não conta com instituição escolar e, sem direção, coordenação ou secretaria escolar, fica vinculado à escola pública estadual mais próxima, local no qual os alunos são matriculados e de onde são enviados relatórios à Secretaria de Educação, material didático, declarações, históricos, dentre outros documentos. Essa parceria, além de não atender às exigências do SINASE, ainda contempla vários problemas sérios que serão mencionados e analisados. Contudo, não há ensino regular na instituição, e os garotos não são previamente avaliados para averiguar em que sala se adequarão melhor. De maneira que, mesmo não havendo distorção da idade com a série, ele será obrigado a se adequar a Educação de Jovens e Adultos (EJA).

O projeto político pedagógico (PPP) da instituição foi enviado pela escola à qual o CEPA está vinculado e não atende às peculiaridades da instituição socioeducativa, configurando-se um documento desatualizado e inoperante. Esse fato prejudica sobremaneira o direcionamento das atividades pedagógicas desenvolvidas pelo setor pedagógico, que demonstra insegurança em verbalizar a filosofia e os demais direcionamentos contidos no PPP, que deveriam estar claros para todos aqueles envolvidos no processo de escolarização.

As professoras do CEPA são todas selecionadas pela Secretaria de Trabalho e Desenvolvimento Social para contrato temporário e não possuem vínculo com escola. Além de não dispor de estabilidade, não contam com apoio de coordenação pedagógica, elaborando seus planos de maneira individual.

O setor pedagógico é constituído apenas por uma pedagoga, uma estagiária de pedagogia e cinco professoras que ministram aulas em dois turnos no CEPA. Observou-se que a qualificação 
para atuar com clientela tão específica, como jovens em conflito com a lei, foi, apenas, mediante estágio e observação da direção por três dias. E que algumas vezes as professoras abandonam o emprego deixando os alunos meses sem aula, por conta do ambiente profissional hostil, como relatado pelas professoras: "Tem que fingir que não está com medo, os meninos são tão inconstantes. [...] A gente tem que trabalhar né?" (Pati); "Eu estou aqui porque é o jeito, se arranjasse coisa melhor saia na hora" (Manu); "A Rita desistiu, ela tinha pesadelo e não conseguia dormir só de pensar que teria que estar aqui no outro dia" (Dami). Entretanto, mesmo diante da insatisfação verbalizada, observou-se que havia muita dedicação e empenho das professoras em desenvolver, na medida do possível, um bom trabalho.

As cinco salas de aula - uma para cada professora - são: pequenas, mas com tamanho razoável por conta do pequeno número de alunos em cada uma delas; bem decoradas, com painéis, alfabetos e cartazes; com iluminação adequada; ventilação precária; e poucas carteiras escolares - sempre queimadas nas rebeliões. Há uma classe para: EJA 1 ( 1 ㅇ e 2 으onos), EJA 2 (3으, 4ㅇ e 5ㅇ) ), EJA 3 (6ㅇ e 7으), EJA 4 ( 8 ㅇ e 9을 e outra para o ensino médio.

Como há revezamento de horário para o comparecimento às aulas, os garotos de cada bloco possuem períodos de aula distintos. A alegação da direção é que essa rotatividade se faz necessária para conseguir obter organização e controle interno, minimizando conflitos. Mas o observado é que ela acarreta inúmeros malefícios, como exemplo se pode citar: as aulas diárias são ministradas em curtíssima duração - apenas uma hora por dia - prejudicando o aprendizado e o desenvolvimento intelectual dos internos, pela necessidade de rodízio.

Agravando o problema da carga horária muito reduzida, ainda existe uma determinação interna que proíbe a entrada de material escolar (livros, lápis, cadernos, dentre outros) e jogos educativos nos dormitórios, o que coíbe o estudo e a pesquisa em horários alternativos ao da sala de aula. Tal procedimento impossibilita o estudo aprofundado de conhecimentos, restringe a quantidade de conteúdos a serem ministrados e não permite, através da leitura de livros literários, a ampliação da cultura discente.

Não há sala de informática e, infelizmente, o professor contratado para o exercício dessa função acaba realizando atividades distintas para contribuir com a instituição e evitar a própria transferência, pois atua como técnico ou auxiliar para outras áreas visto que não há sala equipada para ele ministrar aulas. Consequentemente, os jovens perdem mais essa oportunidade de ocupação e, principalmente, de qualificação para o ingresso nas várias profissões que exigem conhecimento elementar de informática, ficando ainda mais distantes da inserção na sociedade e descumprindo a determinação do ECA de "acesso aos meios de comunicação social".

Outro ambiente importante que não consta no CEPA é a biblioteca. O setor pedagógico alega dois atenuantes para a situação: dificuldade de conseguir livros paradidáticos, pois afirma que estes nunca chegam à instituição; e a necessidade de manter papéis longe dos internos, uma vez que são utilizados para fumar e queimar durante as rebeliões, o que agravaainda mais as consequências dessas manifestações. O observado, no entanto, é que não se dá prioridade de investimento a esse espaço, e que a leitura não se configura importante para a formação cidadã dos jovens, na concepção da diretoria.

Por intermédio das entrevistas com os sete jovens infratores acerca da educação escolar ministrada, objetivando compreender qual a visão que os usuários faziam da escolarização desenvolvida no CEPA, percebeu-se que uma das maiores queixas era referente ao curto tempo em sala de aula. Alguns depoimentos confirmam o exposto: "Mal a gente chega na aula e ela já 
acaba"; É muito pouco tempo, não dá para aprender muita coisa não"; "E uma hora dá pra nada, tia"; "Aprender na aula a gente aprende, mas não é muita coisa não".

A falta de professor bem como a ausência de aula de educação física sistematizada e de informática também foram mencionadas. E reclamaram da impossibilidade de realizar leituras, escrever e usar jogos no dormitório, o que piorava sobremaneira sua estada na instituição, pois permaneciam mais tempo ociosos. "A gente fica preso sem ter o que fazer e fica só pensando besteira"; "Às vezes a gente engabela a professora e rouba uma caneta, papel ou lápis para poder escrever na cela, porque é proibido, mas nós queria"; "se tivesse livro na cela, eu acabaria lendo alguma coisa".

Observa-se um ceticismo no tocante à importância da educação escolar: "Acho que essa educação aqui não muda em nada nossa vida"; "O pior é quando pega castigo ou vai pra tranca, porque fica sem aula e sem lazer"; "Não é por causa dessas aulas aqui que vou conseguir nada diferente lá fora, não"; "Melhor tá na aula que preso, mas não sei se muda muita coisa não".

Concluiu-se com as entrevistas - segundo a visão dos jovens - que a educação escolar pouco contribui nas formações intelectual e cidadã deles e que esta atividade é concebida muito mais como uma forma de escapar da prisão no dormitório do que como um ambiente de crescimento e desenvolvimento pessoal. Desse modo, ficou averiguado que a educação escolar não ocupa papel central na vida dos jovens do CEPA, que não atende as determinações legais e peca no quesito qualidade.

\section{CONSIDERAÇÕES FINAIS}

Mesmo com os avanços obtidos pelo ECA para assegurar atendimento às crianças e adolescentes atores de atos infracionais, na prática, a privação de liberdade persiste como medida socioeducativa amplamente utilizada, mesmo com as recomendações em contrário. Posto que se evidência no Brasil que a questão da infância não tem sido colocada numa perspectiva de estado de direito, mas se tem centrado no autoritarismo, no clientelismo, na repressão e nas concessões limitadas pessoais e arbitrárias visando principalmente à manutenção da ordem pelo disciplinamento (FALEIROS, 2010). Assim sendo, a relação entre cidadania e ordem acaba por gerar uma política repressiva que considera o adolescente infrator como menor ou incapaz, resultando em atendimento jurídico em centros educacionais de ressocialização e "regeneração", em que a participação e o direito das crianças e jovens não estão refletidos na valorização da autonomia, na solidariedade social ou no dever do Estado em proporcionar seus direitos de cidadãos, mas, principalmente, em disciplinar para obediência e aceitação das desigualdades sociais. (FOUCAULT, 2009).

Observa-se que, apesar das juventudes já se constituírem o escopo de diversas políticas governamentais, tais intervenções são idealizadas no âmbito do poder, o qual restringe sua aplicabilidade à verticalidade das ações - de cima para baixo -, não envolvendo na sua elaboração os seus usuários, principalmente no tocante àquelas destinadas a jovens infratores. A política voltada para cidadania, que se idealiza, implica uma relação do Estado para com a criança eo jovem baseada no direito efetivo e na participação social autônoma em que o Estado se obriga não apenas a defender mas também a propiciar de fato os direitos constitucionais.

Nesse cenário, a educação escolar ministrada na instituição de internação possui papel fundamental no debate crítico acerca dos problemas sociais que envolvem os jovens e a sociedade de maneira geral, além de possibilitar o aprendizado em diversas áreas através da 
mediação de conhecimentos. No entanto, a maneira que a educação escolar é ministrada na instituição de internação pouco contribui para formação do indivíduo, pois não contempla sua finalidade legal de desenvolver o educando para o exercício da cidadania e a progressão em estudos posteriores, caracterizando-se pela precária qualidade.

\section{REFERÊNCIAS BIBLIOGRÁFICAS}

1. BRANCO, B. M; WAGNER, A. Os adolescentes infratores e o empobrecimento da rede social quando do retorno à comunidade. Ciência \& Saúde Coletiva, Rio de Janeiro v.14, n.2, mar/abr. 2009.

2. BRASIL. Lei no $\mathbf{8 . 0 6 9}$, de 13 de julho de 1990. Dispõe sobre o Estatuto da Criança e do Adolescente, e dá outras providências, Brasília, DF, Câmara dos Deputados, 1990.

3. Presidência da República. Secretaria Especial dos Direitos humanos. Conselho Nacional dos Direitos da criança e do Adolescente. Sistema Nacional de Atendimento Socioeducativo - SINASE. Brasília, DF: CONADA, 2006.

4. EDUARDO, L. P; EGRY, E. Y. Estatuto da criança e do adolescente: a visão dos trabalhadores sobre sua prática. Revista da Escola de Enfermagem da USP, São Paulo, v.44, n.1, mar. 2010.

5. FALEIRO, E. T. S. Acriança e o adolescente. Objetos sem valor no Brasil Colônia e no Império. In: RIZZINI, I; PILOTTI, F. (Orgs). A arte de governar crianças: a história das políticas sociais, da legislação e da assistência à infância no Brasil. 2 ed. São Paulo:Cortez, 2009.

6. FOUCAULT, M. Vigiar e punir: nascimento da prisão. 37ed. Petrópolis, RJ: Vozes, 2009.

7. LE GOFF, Jacques. História e memória. 5.ed. Campinas: Unicamp, 2003.

8. MATINS, Gilberto de Andrade; THEÓPHILO, Carlos Renato. Metodologia da investigação científica para ciências sociais aplicadas. São Paulo: Atlas, 2007.

9. MESQUITA, Ilka Miglio de; FONSECA, Selva Guimarães. Formação de professores de história: experiências, olhares e possibilidades. História Unisinos, v. 10, n. 3, p. 333-343, set./dez. 2006.

10. MINAYO, M.C. De S. (Org.) Pesquisa Social: Teoria, Método e Criatividade. 22 Ed. Rio De Janeiro: Vozes, 2003

11. OLIVEIRA, M. B; ASSIS, S. G. Os adolescentes infratores do Rio de Janeiro e as instituições que os "ressocializam". A perpetuação do descaso. Cadernos de Saúde Pública, Rio de Janeiro, v.15, n.4, oct/dec. 1999.

12. PRIULI, R. M. A; MORAES, M. S. Adolescentes em conflito com a lei. Ciência \& Saúde Coletiva, Rio de Janeiro, v.12, n.5, set/out. 2007.

13. VIDGAL, L. Os testemunhos orais na escola: história oral e projetos pedagógicos. Lisboa: Edições Asa, 1996. 